\title{
Time- and Temperature-Dependent Luminescence of Manganese Ions in Ceramic Magnesium Aluminum Spinels
}

\author{
Nicholas Khaidukov ${ }^{1}$, Angela Pirri ${ }^{2}$, Maria Brekhovskikh ${ }^{1}$, Guido Toci ${ }^{3}$, Matteo Vannini ${ }^{3}$, Barbara Patrizi ${ }^{3}$ (D) \\ and Vladimir Makhov $4, * \mathbb{E}$ \\ 1 N. S. Kurnakov Institute of General and Inorganic Chemistry, 31 Leninskiy Prospekt, 119991 Moscow, Russia; \\ khaiduk2@gmail.com (N.K.); mbrekh@mail.ru (M.B.) \\ 2 Istituto di Fisica Applicata "N. Carrara", Consiglio Nazionale delle Ricerche, via Madonna del Piano 10, \\ Sesto Fiorentino, 50019 Florence, Italy; pirri@ifac.cnr.it \\ 3 Istituto Nazionale di Ottica, Consiglio Nazionale delle Ricerche, via Madonna del Piano 10, Sesto Fiorentino, \\ 50019 Florence, Italy; guido.toci@ino.cnr.it (G.T.); matteo.vannini@ino.it (M.V.); \\ barbara.patrizi@ino.cnr.it (B.P.) \\ 4 P. N. Lebedev Physical Institute, 53 Leninskiy Prospekt, 119991 Moscow, Russia \\ * Correspondence: makhovvn@lebedev.ru; Tel.: +7-499-132-6575
}

check for

updates

Citation: Khaidukov, N.; Pirri, A.; Brekhovskikh, M.; Toci, G.; Vannini, M.; Patrizi, B.; Makhov, V. Time- and Temperature-Dependent Luminescence of Manganese Ions in Ceramic Magnesium Aluminum Spinels. Materials 2021, 14, 420. https://doi.org/10.3390/ma14020420

Received: 15 December 2020 Accepted: 12 January 2021 Published: 16 January 2021

Publisher's Note: MDPI stays neutral with regard to jurisdictional clai$\mathrm{ms}$ in published maps and institutional affiliations.

Copyright: $(2021$ by the authors. Licensee MDPI, Basel, Switzerland. This article is an open access article distributed under the terms and conditions of the Creative Commons Attribution (CC BY) license (https:// creativecommons.org/licenses/by/ $4.0 /)$.

\begin{abstract}
Samples of magnesium aluminum spinel ceramics doped with manganese ions were prepared by a high-temperature solid-state reaction method; their potential as red-emitting phosphors was analyzed using a time-resolved luminescence spectroscopy technique, from room temperature to $10 \mathrm{~K}$. It was found that in the red spectral range, the luminescence spectra of manganese ions in the $\mathrm{MgAl}_{2} \mathrm{O}_{4}$ spinel showed a narrow band peaking at $651 \mathrm{~nm}$ due to the emission of $\mathrm{Mn}^{4+}$ and a broader emission band in the region of $675 \div 720 \mathrm{~nm}$; the ratio of intensities for these bands depends on the synthesis conditions. By applying a special multi-step annealing procedure, the $\mathrm{MgAl}_{2} \mathrm{O}_{4}: \mathrm{Mn}^{4+}$ phosphor containing only tetravalent manganese ions, $\mathrm{Mn}^{4+}$, was synthesized. Broad-band far-red emission observed from $\mathrm{MgAl}_{2} \mathrm{O}_{4}: \mathrm{Mn}$ and $\mathrm{Mg}_{1.25} \mathrm{Al}_{1.75} \mathrm{O}_{3.75} \mathrm{~F}_{0.25}$ :Mn phosphors, prepared by a conventional method of a solid-state reaction, was interpreted as coming from $\mathrm{Mn}^{3+}$ ions.
\end{abstract}

Keywords: spinel; ceramics; photoluminescence; time-resolved spectroscopy; red-emitting $\mathrm{Mn}^{4+}$ phosphors; phosphor-converted LED

\section{Introduction}

At present, the development of phosphors for application in phosphor-converted white Light Emitting Diodes (pc-WLEDs) is one of the most relevant areas of research in lighting technologies. In particular, since the introduction of the first commercial pcWLEDs, a search for new efficient red light-emitting phosphors has been actively ongoing. Indeed, a significant contribution in the red region of the emission spectrum is highly required to obtain warm white light from pc-WLEDs based on the standard technology exploiting the combination of a blue LED chip and a converting yellow YAG:Ce ${ }^{3+}$-type phosphor [1]. A suitable phosphor should have significant absorption in the blue spectral range and emit in the red (i.e., in the $620 \div 650 \mathrm{~nm}$ range) [2]. In particular, in most commercial pc-WLEDs, some nitride compounds doped with $\mathrm{Eu}^{2+}$ rare earth ions are used as red phosphors [3]. However, the band width of the emission due to the $\mathrm{Eu}^{2+}$ $5 \mathrm{~d}-4 \mathrm{f}$ electronic transition is relatively large, which results in partial emission outside the red region and, as a consequence, a decrease in the luminous efficacy of the red-emitting phosphor [3]. $\mathrm{Mn}^{4+}$-doped luminescent materials with narrow-band emission due to $\mathrm{Mn}^{4+} \mathrm{d}$-d electronic transition have been subjected to intensive studies in the last years as promising red-emitting phosphors under excitation with blue/near UV LEDs.

Among these, in recent years, several red-emitting phosphors doped with $\mathrm{Mn}^{4+}$ have been developed. The attention was mainly oriented to fluoride compounds: here, 
$\mathrm{Mn}^{4+}$ shows a narrow emission band near $630 \mathrm{~nm}$, which is about optimal for lighting applications. [4]. On the other hand, some drawbacks (e.g., a need for toxic hydrofluoric acid for their synthesis, poor resistance to temperature and humidity) seriously hamper their development. For this reason, at a recent time, studies have also been addressing other candidate hosts such as oxides and oxyfluorides [2,5].

Among oxides, special attention is paid to aluminates in which $\mathrm{Mn}^{4+}$ ions substitute for the $\mathrm{Al}^{3+}$ ions in octahedral sites. $\mathrm{Mn}^{4+}$ and $\mathrm{Al}^{3+}$ have very similar ionic radii but some kind of charge compensation is needed for the stabilization of $\mathrm{Mn}^{4+}$ ions in octahedral sites. The properties of $\mathrm{Mn}^{4+}$ luminescence in different aluminate hosts are described in several review papers (see, e.g., [2]). In particular, $\mathrm{Mn}^{4+}$-doped aluminates whose structures have spinel structured blocks, i.e., the close-packed oxygen layers with $\mathrm{Al}^{3+}$ or $\mathrm{Al}^{3+}$ and $\mathrm{Mg}^{2+}$ in octahedral and tetrahedral sites, were extensively investigated. Such phosphors show luminescence of $\mathrm{Mn}^{4+}$ ions within the red spectral range, namely, $\mathrm{SrMgAl}_{10} \mathrm{O}_{17}$ (658 nm) [6], $\mathrm{BaMgAl}_{10} \mathrm{O}_{17}(660 \mathrm{~nm})$ [7], $\mathrm{Sr}_{2} \mathrm{MgAl}_{22} \mathrm{O}_{36}(659 \mathrm{~nm})$ [8], $\mathrm{Ca}_{2} \mathrm{Mg}_{2} \mathrm{Al}_{28} \mathrm{O}_{46}$ (656 nm) [9], $\mathrm{CaMg}_{2} \mathrm{Al}_{16} \mathrm{O}_{27}(655 \mathrm{~nm})$ [9], $\mathrm{Sr}_{4} \mathrm{Al}_{14} \mathrm{O}_{25}$ (654 nm) [10], $\mathrm{Sr}_{2} \mathrm{Al}_{6} \mathrm{O}_{11}$ (652 nm) [11], $\mathrm{CaAl}_{12} \mathrm{O}_{19}$ $(658 \mathrm{~nm})$ [12], $\mathrm{SrAl}_{12} \mathrm{O}_{19}(658 \mathrm{~nm})$ [13], and $\mathrm{LaMgAl}_{11} \mathrm{O}_{19}(663 \mathrm{~nm})$ [14], quite near the edge of eye sensitivity. However, probably the shortest wavelength of $\mathrm{Mn}^{4+}$ luminescence in aluminate hosts is observed for the classical 'spinel' $\mathrm{MgAl}_{2} \mathrm{O}_{4}$ [15-18].

Compounds of the spinel group, in particular, the 'spinel' itself $\mathrm{MgAl}_{2} \mathrm{O}_{4}$, are wellknown matrices for developing phosphors. For instance, the $\mathrm{MgAl}_{2} \mathrm{O}_{4}$ spinel features a cubic structure ( $F d \overline{3} m$ space group); in this structure, oxygen anions have a cubic close packing arrangement which creates tetrahedrally and octahedrally coordinated cavities for $\mathrm{Mg}^{2+}$ and $\mathrm{Al}^{3+}$ cations, respectively [19]. In this structure, $\mathrm{Mg}^{2+}$ and $\mathrm{Al}^{3+}$ can exchange their positions in the lattice. Therefore, the distribution of cations can be described with the formula $\left(\mathrm{Mg}_{1-x} \mathrm{Al}_{\mathrm{x}}\right)\left[\mathrm{Mg}_{\mathrm{x}} \mathrm{Al}_{2-\mathrm{x}}\right]_{\mathrm{O}_{4}}$, where $x$ is an index expressing the inversion degree. As a result, the spinel crystal structure is disordered, similar to what is observed in solid solutions. Nevertheless, it is generally accepted that this cation inversion allows the fabrication of spinel phosphors where the tetravalent $\mathrm{Mn}^{4+}$ ions substitute for $\mathrm{Al}^{3+}$ ions. This is obtained by introducing an equivalent concentration of $\mathrm{Mg}^{2+}$ ions at the octahedral site. The excess $\mathrm{Mg}^{2+}$ ions compensate for the charge unbalance, still maintaining the stoichiometry with respect to oxygen ions in the spinel crystal lattice $[15,16]$.

In our previous studies it was demonstrated that the synthesis parameters strongly affect the luminescence properties of $\mathrm{MgAl}_{2} \mathrm{O}_{4}$ doped with manganese [17,18]. An efficient red-emitting phosphor based on a manganese-doped $\mathrm{MgAl}_{2} \mathrm{O}_{4}$ spinel, with a luminescence peak located at $\sim 651 \mathrm{~nm}$, was prepared by means of a low-temperature annealing phase followed by high-temperature annealing, in an oxidizing atmosphere (air). The low-temperature phase allows for efficient entering of $\mathrm{Mn}^{4+}$ in the octahedral sites. The stabilization of $\mathrm{Mn}^{4+}$ ions at octahedral sites is obtained, taking advantage of the presence of additional $\mathrm{Mg}^{2+}$ ions at octahedral sites, which compensate for the charge unbalance of the lattice structure. Conversely, $\mathrm{Mn}^{2+}$ located in the tetrahedral sites produces only pure green $\left(525 \mathrm{~nm}\right.$ ) emission as observed from a manganese-doped $\mathrm{MgAl}_{2} \mathrm{O}_{4}$ spinel synthesized in a reducing $\mathrm{CO}$ atmosphere, even if $\mathrm{MnO}_{2}$ is used as a dopant. On the other hand, by using $\mathrm{MnO}_{2}$ or $\mathrm{Mn}_{2} \mathrm{O}_{3}$ as dopants, synthesis in neutral argon atmosphere or synthesis without meticulously performed preliminary low-temperature annealing results in the presence of both $\mathrm{Mn}^{2+}$ and $\mathrm{Mn}^{4+}$ in the spinel phosphor as well as the appearance of the other optical centers showing additional emissions; in particular, some broad-band luminescence located at longer wavelengths in the red region is detected. The nature of this far-red broad-band emission of manganese ions in $\mathrm{MgAl}_{2} \mathrm{O}_{4}$ phosphors remains unclear, thus further investigations are required.

In the present work, the luminescence properties of a series of ceramic spinel $\mathrm{MgAl}_{2} \mathrm{O}_{4}$ phosphors doped with manganese ions and prepared under different synthesis conditions were studied by low-temperature and time-resolved spectroscopy. 


\section{Materials and Methods}

The ceramic samples with the spinel lattice structure were synthesized using $\mathrm{MgCO}_{3}$ (purity of $99.99 \%$ ) and $\mathrm{Al}_{2} \mathrm{O}_{3}\left(99.99 \%\right.$ ) as well as $\mathrm{MnO}_{2}(99.999 \%$ ) as a source of manganese ions, by means of a high-temperature solid-state reaction. The starting compounds were weighed to obtain the composition $\mathrm{Mg}_{1.002} \mathrm{Al}_{1.996} \mathrm{Mn}_{0.002} \mathrm{O}_{4}$, then mixed in ethanol by using a mortar and a pestle made of agate. The mixture was then dried and uniaxially pressed under about $150 \mathrm{MPa}$ in a stainless-steel die. The resulting pellets were about $2 \mathrm{~mm}$ thick and had a diameter of $10 \mathrm{~mm}$. After pressing, the pellets were then placed in a corundum crucible (Thermokeramika, Moscow, Russian Federation). Sample I was subjected to the low-temperature annealing process (consisting of several annealing phases carried out at progressively increasing temperatures, i.e., 500,600 , and $700{ }^{\circ} \mathrm{C}$ ) and then to the high-temperature annealing process (annealing steps at 1000, 1200, and $1300^{\circ} \mathrm{C}$ ). Each temperature step lasted for $4 \mathrm{~h}$, in an oxidizing air atmosphere. Conversely, sample II was synthesized without low-temperature annealing. Before each annealing step the tablets were reground and re-pelletized. Moreover, in the last annealing we added to the samples $3 \mathrm{wt} \% \mathrm{H}_{3} \mathrm{BO}_{3}$ as flux. One more spinel-structured ceramics doped with manganese ions was prepared by using the mixture of sample II, $\mathrm{MgO}$ and $\mathrm{MgF}_{2}$ in weighed amounts corresponding to the composition of $\mathrm{Mg}_{1.25} \mathrm{Al}_{1.75} \mathrm{O}_{3.75} \mathrm{~F}_{0.25}$ (sample III). This mixture was used to obtain pressed pellets which were subjected to annealing at $1200{ }^{\circ} \mathrm{C}$ in an argon atmosphere. The sintered pellets of all samples were finally polished for the following characterization. The thermal treatment used for the three types of samples studied in the present work is presented in Table 1.

Table 1. Experimental conditions applied for the synthesis of ceramic spinels containing manganese ions.

\begin{tabular}{cccc}
\hline Sample Label & Host & Atmosphere & Annealing Temperature $\left({ }^{\circ} \mathbf{C}\right)$ \\
\hline Sample I & $\mathrm{MgAl}_{2} \mathrm{O}_{4}$ & air & $500,600,700$ and 1000, 1200, 1300 \\
Sample II & $\mathrm{MgAl}_{2} \mathrm{O}_{4}$ & air & $1000,1200,1300$ \\
Sample III & $\mathrm{Mg}_{1.25} \mathrm{Al}_{1.75} \mathrm{O}_{3.75} \mathrm{~F}_{0.25}$ & argon & 1200 \\
\hline
\end{tabular}

The structural-phase composition of the obtained ceramic samples was studied using a Bruker D8 Advance X-ray powder diffractometer (Billerica, MA, USA) with monochromatic $\mathrm{CuK} \alpha$ radiation, whose voltage and current were set as $40 \mathrm{kV}$ and $40 \mathrm{~mA}$, respectively. XRD data were recorded in the $2 \theta$ range from $10^{\circ}$ to $100^{\circ}$, with the continuous scan mode at a speed of $0.2 \mathrm{~s}$ per step with a step size of $0.02^{\circ}$. Identification of the synthesized compounds was performed with the software package EVA (Bruker) using the ICDD PDF-2 database. The X-ray diffraction analysis confirmed that all the ceramic samples under test had a lattice structure belonging to the cubic system and corresponding to the spinel structure (Figure 1). The unit cubic cell of the various samples had a lattice parameter in the range of $8.07 \div 8.09 \AA$ depending on the synthesis conditions.

Time-resolved photoluminescence (PL) spectroscopy was carried out using a JOBINYVON SPEX TRIAX 320 spectrometer (Edison, NJ, USA), equipped with a $300 \mathrm{~L} / \mathrm{mm}$ grating and using an input slit width of $40 \mu \mathrm{m}$, resulting in an overall spectral resolution of $0.6 \mathrm{~nm}$. The temperature $\mathrm{T}$ of the samples was set in the interval from $\mathrm{T} \sim 10 \mathrm{~K}$ to T $290 \mathrm{~K}$ using a CTI-CRYOGENICS optical cryostat cooled (Mansfield, MA, USA) with a closed cycle refrigerator. For the time-resolved studies (luminescence time decay behavior and time-resolved spectra), pulsed laser excitation was used (wavelength $262 \mathrm{~nm}$, pulse duration $10 \mathrm{~ns}$ ). For this purpose, a frequency quadrupled Nd:YLF laser was used as the excitation source. To reject the ultraviolet radiation scattered by the sample, a long pass filter (made of Schott GG435 glass) was placed in front of the spectrometer entrance slit. The luminescence time decay behaviors were acquired by means of a photomultiplier tube (Thorn EMI 9816QB, Hayes, UK). A digital sampling scope (Tektronix TDS 680B, Heerenveen, The Netherlands) connected to a PC was used to record the decay curves. The 
spectral acquisition bandwidth was set between 2 and $4 \mathrm{~nm}$ by adjusting the spectrometer exit slit width, depending on the signal intensity. The acquisition of the time-gated spectra was carried out using an optical multichannel detector (detector head EG\&G 1420, with a controller EG\&G OMA2000, Gaithersburg, MA, USA) with image intensification and time-gating capabilities, featuring a spectral resolution (pixel bandwidth) of $0.51 \mathrm{~nm}$. The delay of the time acquisition gate with respect to the laser pulse excitation and the gate width were set by means of using a Stanford DG535 delay generator (Sunnyvale, CA, USA). No correction was applied for the spectral sensitivity of the detector, which decreases very sharply for wavelengths longer than about $730 \mathrm{~nm}$. This feature can remarkably distort the long-wavelength part of the measured spectra. The working spectral span of the multichannel detector EG\&G 1420 is $\sim 320 \mathrm{~nm}$. Accordingly, for obtaining PL spectra in the wide spectral range of $350-850 \mathrm{~nm}$, the measurements were performed for two positions of the monochromator corresponding to two values of the central wavelength of the detector spectral span: 650 and $500 \mathrm{~nm}$. Photo-luminescence excitation (PLE) spectra were measured at $300 \mathrm{~K}$ using a spectrofluorometer CM2203 (Solar, Minsk, Republic of Belarus).

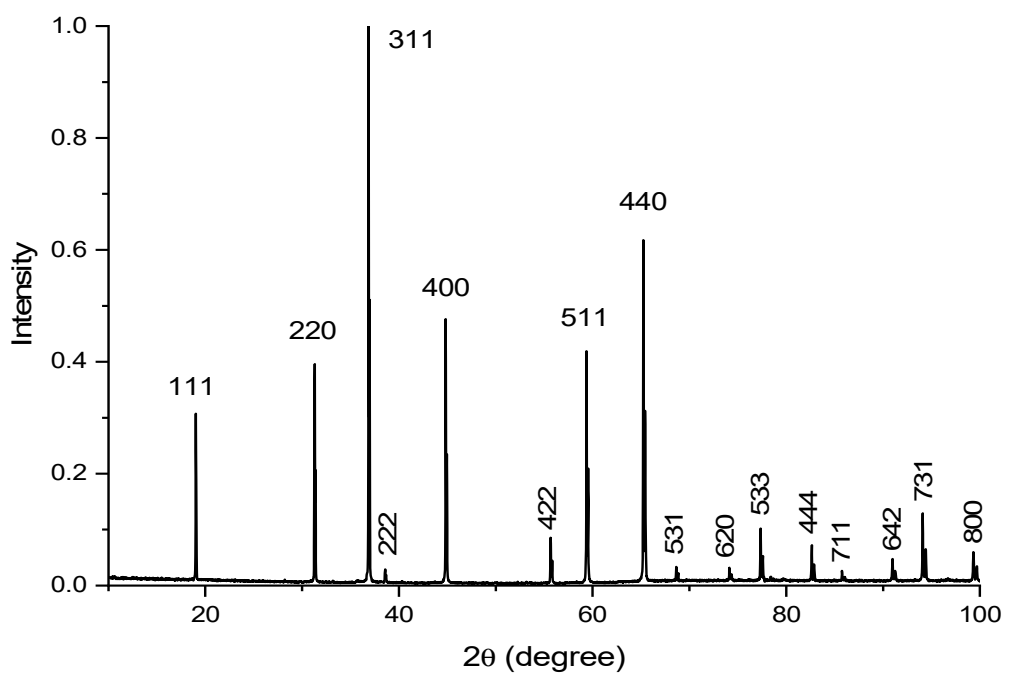

Figure 1. X-ray diffraction pattern of the $\mathrm{MgAl}_{2} \mathrm{O}_{4}$ spinel doped with $0.2 \mathrm{~mol} \% \mathrm{MnO}_{2}$ (sample I). The labels on the peaks are the Miller indices of the corresponding lattice planes.

\section{Results}

The ceramic samples of the manganese ion-doped $\mathrm{MgAl}_{2} \mathrm{O}_{4}$ spinel labeled as sample I were prepared by using $\mathrm{MnO}_{2}$ as a dopant and using firstly the annealing in air at low temperatures (steps at $500,600,700^{\circ} \mathrm{C}$ ) and after that the annealing at higher temperatures (steps at $1000,1200,1300^{\circ} \mathrm{C}$ ). The use of this elaborate annealing scheme was motivated by the necessity of obtaining the stabilization of the $\mathrm{Mn}^{4+}$ ions at the octahedral site. Indeed, manganese (IV) dioxide begins to decompose at $535{ }^{\circ} \mathrm{C}$ to manganese (III) oxide and oxygen [20]. The highest intensity of red emission from $\mathrm{Mn}^{4+}$ in $\mathrm{MgAl}_{2} \mathrm{O}_{4}$ was achieved by the final annealing at $1300{ }^{\circ} \mathrm{C}$ with the addition of boric acid $\left(\mathrm{H}_{3} \mathrm{BO}_{3}\right)$ as flux.

When excited at $262 \mathrm{~nm}$ wavelength, the PL spectrum of sample I, see Figure 2a, is dominated by a relatively broad emission in the red, with a narrow peak at $651 \mathrm{~nm}$. The full-width at half maximum (FWHM) of this peak is $\sim 40 \mathrm{~nm}$ at $290 \mathrm{~K}$. According to many previous publications, the observed red emission corresponds well with the luminescence of $\mathrm{Mn}^{4+}$ [15-18], although a broad-band emission in the blue-green peaking at $430 \mathrm{~nm}$ is also observed under $262 \mathrm{~nm}$ excitation wavelength. The measurements in the shortwavelength region were performed only for three selected temperatures: 200,80 , and $10 \mathrm{~K}$. The $430 \mathrm{~nm}$ band is not detected under $\mathrm{Mn}^{4+}$ intracenter excitation in the near UV/blue spectral region as was shown in previous publications $[17,18]$. Since this $430 \mathrm{~nm}$ emission is observed from all the synthesized samples of $\mathrm{MgAl}_{2} \mathrm{O}_{4}$, doped with manganese ions, 
under $262 \mathrm{~nm}$ excitation wavelength, it can tentatively be attributed to some kind of spinel defect-related emission. Accordingly, it is not relevant for practical applications in LEDs, where the excitation occurs in the blue or near UV spectral range.

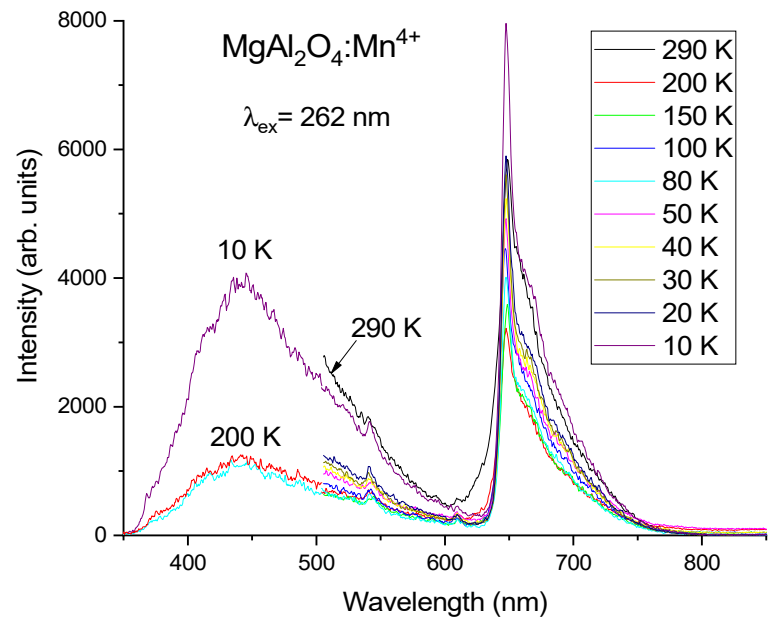

(a)

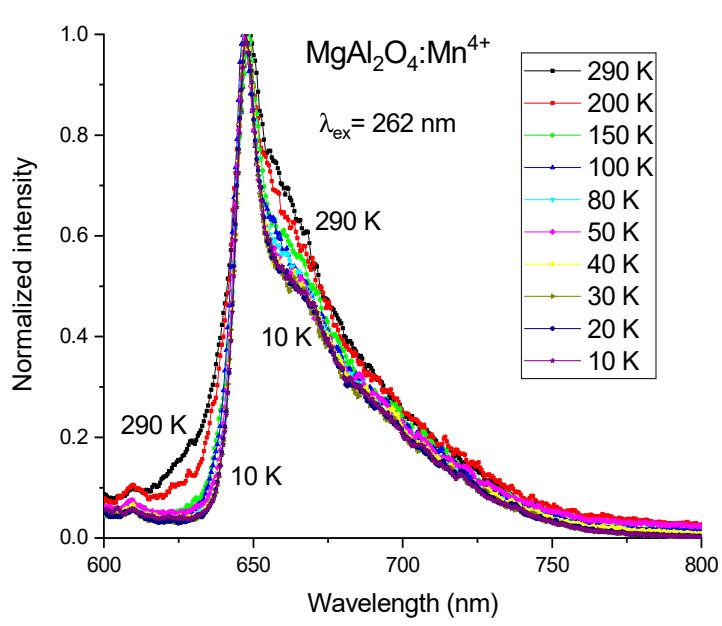

(b)

Figure 2. (a) PL spectra of $\mathrm{MgAl}_{2} \mathrm{O}_{4}: \mathrm{Mn}^{4+}$ (sample I) measured at different temperatures: 290, 200, 150, 100, 80, 50, 40, 30, 20, and $10 \mathrm{~K}$; (b) PL spectra of $\mathrm{MgAl}_{2} \mathrm{O}_{4}: \mathrm{Mn}^{4+}$ (sample I), normalized at their peak value, for the red spectral region measured at different temperatures.

Under cooling, the PL spectrum of sample I becomes narrower and the short-wavelength wing of the spectrum practically disappears at $10 \mathrm{~K}$, see Figure $2 \mathrm{~b}$. Due to the small relative movements of the sample with respect to the laser beam and collection optics during the cooling phase, affecting the signal collection efficiency, it was not possible to compare the absolute luminescence intensity at different temperatures in Figure 2a. For this reason, in Figure 2b, the spectra normalized to the maximum intensity of the peak at $651 \mathrm{~nm}$ are presented for the most important red spectral region.

The time-resolved PL spectra from sample I have been measured at a room temperature with time delays between 0 and $1 \mathrm{~ms}$ and with a time gate width of $1 \mathrm{~ms}$, see Figure 3 . The spinel defect-related broad-band emission disappears already at the shortest delay value $0.1 \mathrm{~ms}$, i.e., this emission has a rather fast decay and does not influence the PL spectrum at longer delays. The decay time of this defect-related emission is estimated to be $\sim 5 \mu \mathrm{s}$. Due to this reason, the time-resolved PL spectra were not studied in the spectral range shorter than $500 \mathrm{~nm}$ with the position of central wavelength of the detector at $500 \mathrm{~nm}$. The normalized time-resolved PL spectra show that the shape of PL spectrum does not change with the time delay, i.e., luminescence within the whole PL spectrum decays with the same decay law and accordingly corresponds to the decay of the same emitting state.

Decay curves of the red luminescence acquired at different values of temperature after pulsed excitation at $262 \mathrm{~nm}$ show non-exponential behavior, see Figure 4, which indicates the presence of some kind of extrinsic quenching of the luminescence, probably due to the energy transfer from $\mathrm{Mn}^{4+}$ ions to some quenching centers originated by defects. The obtained decay curves were fitted by a double exponential decay function. The value of the longer decay component, which can be considered an estimation of intrinsic radiative decay time, is $\sim 0.4 \mathrm{~ms}$ at $290 \mathrm{~K}$ and practically it does not change with temperature. 


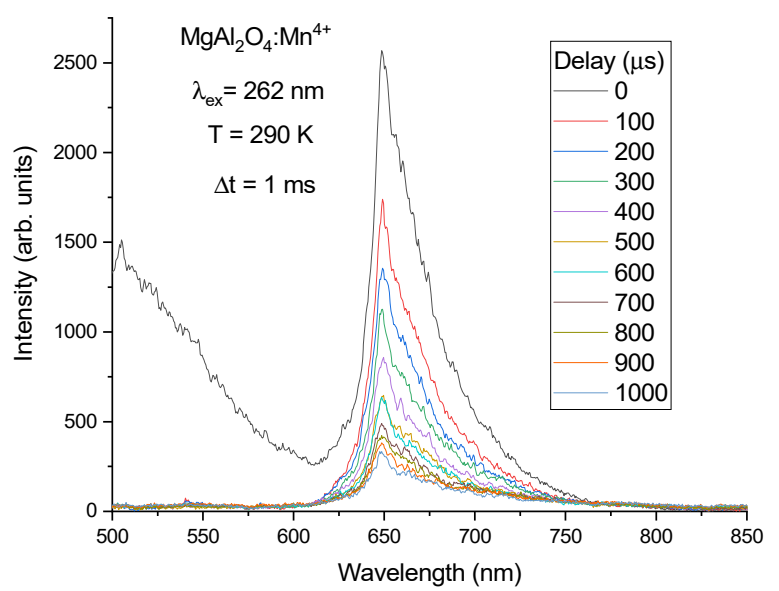

(a)

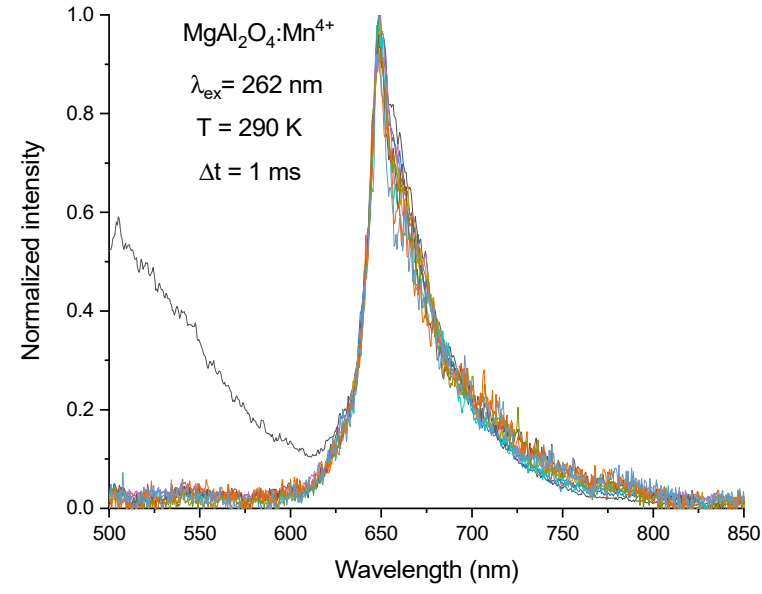

(b)

Figure 3. (a) Time-resolved PL spectra of the spinel $\mathrm{MgAl}_{2} \mathrm{O}_{4}$ ceramics doped with $0.2 \mathrm{~mol} \% \mathrm{MnO}_{2}$ (sample I) measured at $290 \mathrm{~K}$ with different delays $(0-1 \mathrm{~ms})$ between the laser pulse and the time gate $(\Delta \mathrm{t}=1 \mathrm{~ms})$; $(\mathbf{b})$ the same spectra normalized to the peak intensity.

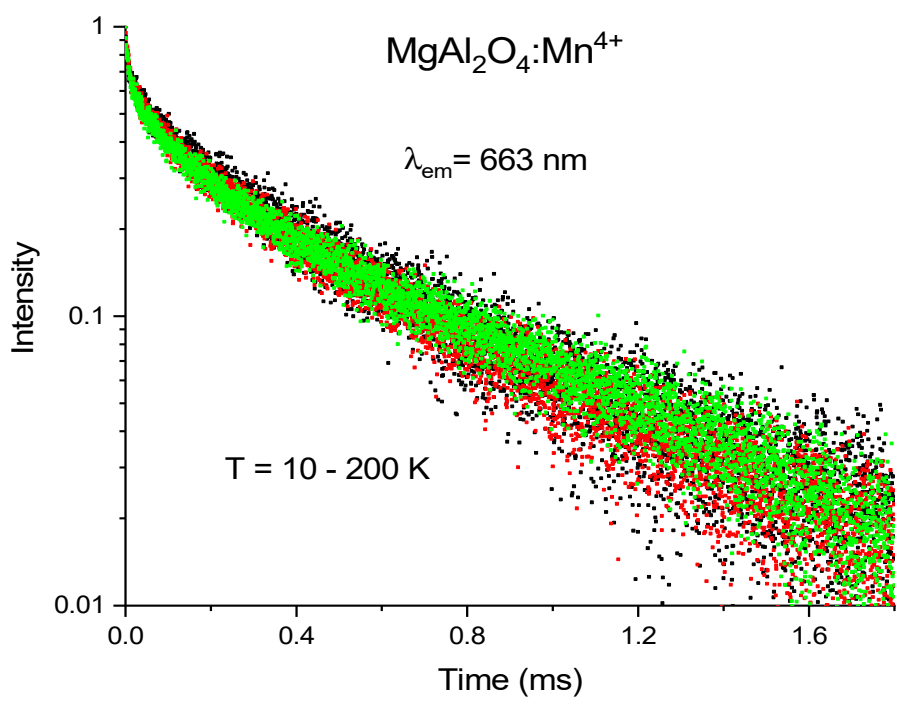

Figure 4. Normalized decay curves of red $\left(\lambda_{\mathrm{em}}=663 \mathrm{~nm}\right)$ luminescence recorded from sample I, $\mathrm{MgAl}_{2} \mathrm{O}_{4}$ doped with $0.2 \mathrm{~mol} \% \mathrm{MnO}_{2}$, at $\mathrm{T}$ from $10 \mathrm{~K}$ to $200 \mathrm{~K}$.

On the other hand, in $\mathrm{MnO}_{2}$ doped $\mathrm{MgAl}_{2} \mathrm{O}_{4}$ samples subjected to the high temperature annealing only (temperature steps at 1000,1200 , and $1300{ }^{\circ} \mathrm{C}$ ) but without the low temperature preliminary annealing phase (sample II), the luminescence of $\mathrm{Mn}^{4+}$ ions in the red at $651 \mathrm{~nm}$ practically disappears: in the red region the PL spectrum is mainly constituted by the broad-band far-red luminescence band having a maximum between $690 \div 710 \mathrm{~nm}$; moreover, an additional green luminescence peak appears at $520 \mathrm{~nm}$, see Figure 5. As it is well-known, the luminescence of manganese ions doped $\mathrm{MgAl}_{2} \mathrm{O}_{4}$ in the green is due to the ${ }^{4} \mathrm{~T}_{1} \rightarrow{ }^{6} \mathrm{~A}_{1}$ transition of $\mathrm{Mn}^{2+}$ ions occupying the tetrahedral sites by substituting for $\mathrm{Mg}^{2+}$ ions in the spinel $[15,21]$. The PLE spectrum of $\mathrm{Mn}^{2+}$, reported in Figure 6, has a characteristic shape featuring four clearly distinguishable bands in the range $350 \div 470 \mathrm{~nm}$. One of these bands, typically located near $400 \mathrm{~nm}$ (in our case at $430 \mathrm{~nm}$ ) is rather narrow. The increasing intensity of the green emission at wavelengths shorter than $290 \mathrm{~nm}$ is not due to an increase of the $\mathrm{Mn}^{2+}$ luminescence intensity but is caused by the appearance of the broad-band defect-related emission, whose PL spectrum overlaps with that of $\mathrm{Mn}^{2+}$ luminescence. The latter circumstance does not allow studying the spectral 
properties of $\mathrm{Mn}^{2+}$ luminescence under $262 \mathrm{~nm}$ laser excitation separately from those of this defect-related emission.

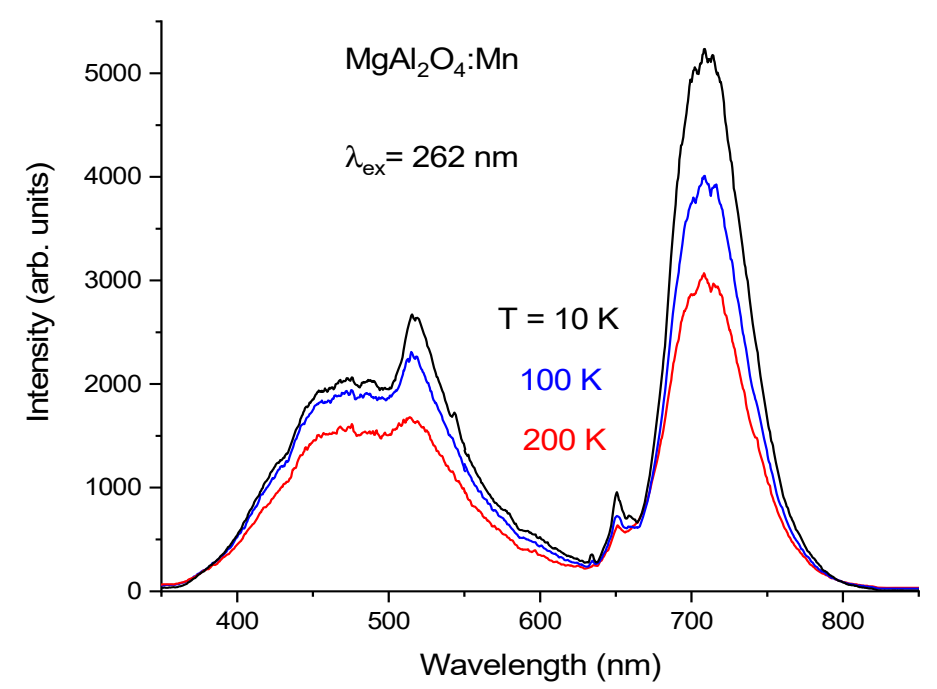

Figure 5. PL spectra of sample II, i.e., $\mathrm{MgAl}_{2} \mathrm{O}_{4}: \mathrm{Mn}$, measured at different temperatures: $200 \mathrm{~K}$, $100 \mathrm{~K}$, and $10 \mathrm{~K}$.

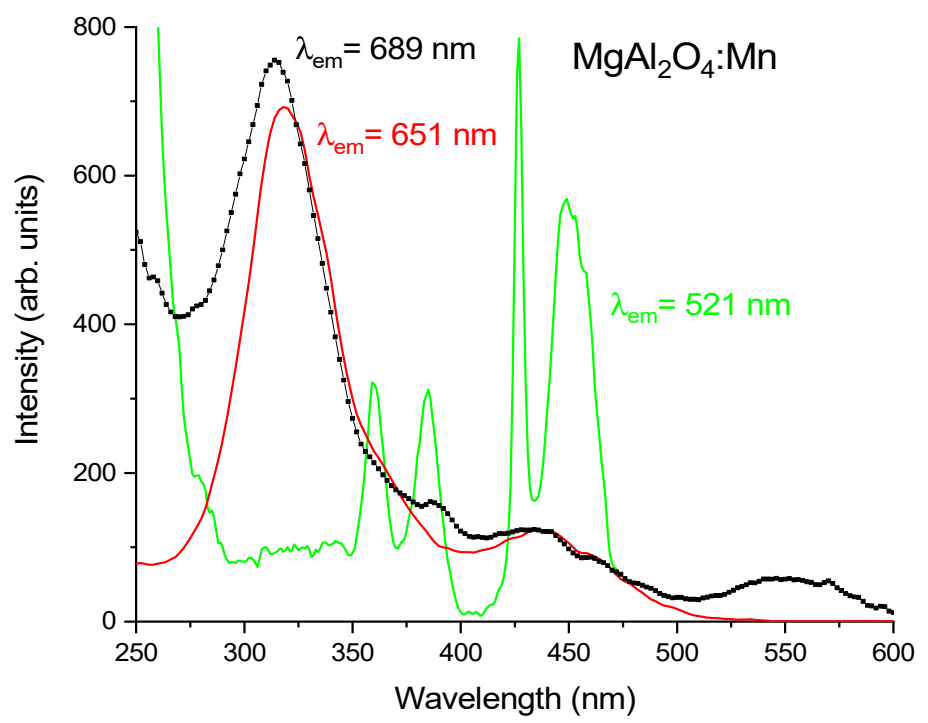

Figure 6. PLE spectra of sample II, i.e., $\mathrm{MgAl}_{2} \mathrm{O}_{4}: \mathrm{Mn}$, measured at $290 \mathrm{~K}$ by monitoring different emission wavelengths.

We note that the PLE spectrum of the emission band in the red with maximum at $651 \mathrm{~nm}$ (see Figure 6, red line) has two excitation bands in the blue (peaking at $446 \mathrm{~nm}$ ) and near UV (peaking at $364 \mathrm{~nm}$ ). Referring to the scheme of the energy levels of $\mathrm{Mn}^{4+}$ provided by the Tanabe-Sugano (TS) diagram for the $\mathrm{d}^{3}$ electron configuration under an octahedral crystal field (CF) [22], these bands can be attributed to the spin-allowed transitions of $\mathrm{Mn}^{4+}$, namely, ${ }^{4} \mathrm{~A}_{2} \rightarrow{ }^{4} \mathrm{~T}_{2}$ and ${ }^{4} \mathrm{~A}_{2} \rightarrow{ }^{4} \mathrm{~T}_{1}$, respectively. Additionally, the observed excitation band with a peak near $325 \mathrm{~nm}$ is due to the $\mathrm{O}^{2-}-\mathrm{Mn}^{4+}$ charge-transfer transition. On the other hand, according to Figure 6, the PLE spectrum of broad-band far-red emission coincides with that of $\mathrm{Mn}^{4+}$ luminescence in the range of $300 \div 500 \mathrm{~nm}$, i.e., in the region of $\mathrm{Mn}^{4+}$ strong absorption on spin-allowed $\mathrm{d}-\mathrm{d}$ and fully allowed charge-transfer transitions. Some difference in PLE spectra is observed at wavelengths shorter than $300 \mathrm{~nm}$, in particular, around the excitation laser wavelength and in the range of $\lambda>500 \mathrm{~nm}$. 
When the temperature increases from $10 \mathrm{~K}$ to $200 \mathrm{~K}$, the intensities of both the broadband far-red luminescence as well as $\mathrm{Mn}^{2+}$ green emission decrease but not so strongly as that of $\mathrm{Mn}^{4+}$ luminescence, traces of which can also be seen near $650 \mathrm{~nm}$ in the PL spectrum of sample II (Figure 5). The decay time of the broad-band far-red luminescence at $290 \mathrm{~K}$ has been estimated to be $\tau \sim 4.0 \mathrm{~ms}$. Time-resolved PL spectra measured for sample II in the time delay range of $0 \div 2.5 \mathrm{~ms}$ confirm that the broad-band far-red luminescence has a longer decay time than $\mathrm{Mn}^{4+}$ luminescence and that the latter decays completely at longer time delays (see Figure 7). As in the case of sample I, the spinel defect-related emission disappears from the spectrum of sample II at the shortest time delay of $0.1 \mathrm{~ms}$, and the $\mathrm{Mn}^{2+}$ luminescence band at $520 \mathrm{~nm}$ can be better recognized in the time-resolved PL spectra where this luminescence is still observable at long time delays (decay time is in the order of several ms). Again, as in the case of sample I, the time-resolved PL spectra were not studied in the spectral range shorter than $500 \mathrm{~nm}$.

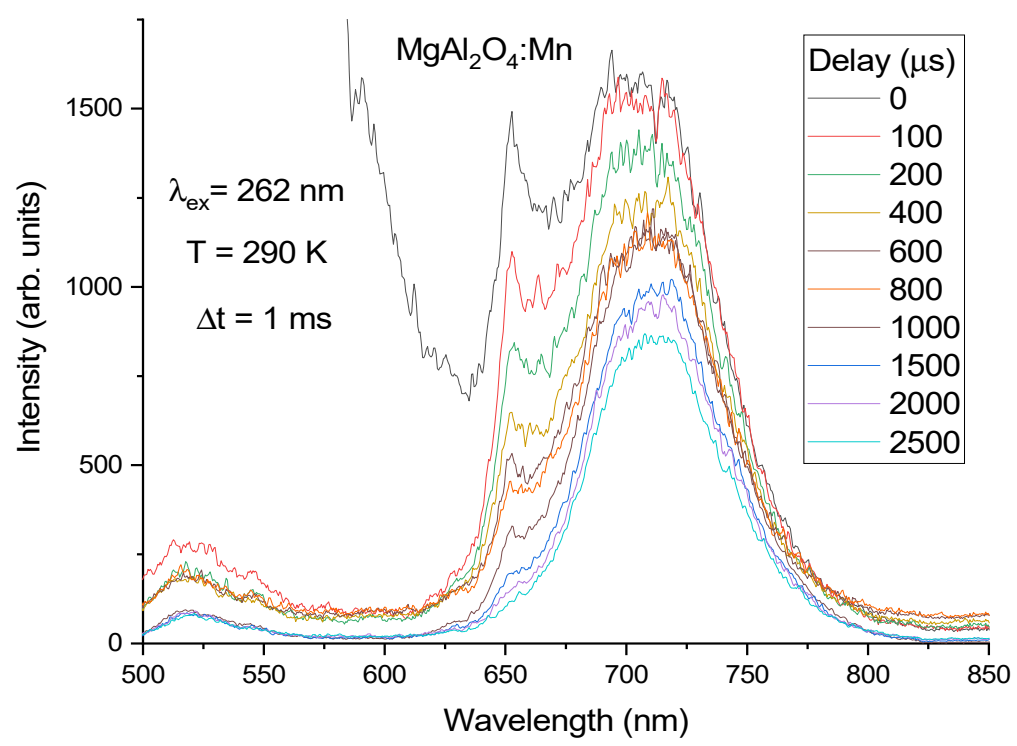

Figure 7. Time-resolved PL spectra of $\mathrm{MgAl}_{2} \mathrm{O}_{4}: \mathrm{Mn}$ (sample II) measured at $290 \mathrm{~K}$ at different delays $(0 \div 2.5 \mathrm{~ms})$ of the time gate $(\Delta \mathrm{t}=1 \mathrm{~ms})$ with respect to the laser pulse.

One more peculiarity of magnesium aluminate spinels doped with manganese ions is that the increasing ratio of $\mathrm{Mg}^{2+}$ to $\mathrm{Al}^{3+}$ results in the magnification of the $\mathrm{Mn}^{4+} \mathrm{lu}^{-}$ minescence intensity even if the synthesis of such spinels is carried out in a neutral argon atmosphere. Figure 8 reports the luminescence spectra of manganese ions doped $\mathrm{Mg}_{1.25} \mathrm{Al}_{1.75} \mathrm{O}_{3.75} \mathrm{~F}_{0.25}$ spinel (sample III) synthesized in argon by using $\mathrm{MgAl}_{2} \mathrm{O}_{4}$ : $\mathrm{Mn}$ (sample II) as a starting material. The measurements in the short-wavelength region were performed only for three selected temperatures: 200, 80, and $10 \mathrm{~K}$. One can see that in sample III, the $\mathrm{Mn}^{4+}$ luminescence intensity relative to the intensity of the broad-band far-red luminescence is more intense than in sample II, taking into account that the intensities of the broad-band far-red luminescence in these samples have practically the same values. It should also be noted that the ratio of the intensities for the luminescence bands at 651 and $700 \mathrm{~nm}$ for sample III is almost constant in the range of temperature from $10 \mathrm{~K}$ to $200 \mathrm{~K}$.

In order to demonstrate the difference between the position and relative intensities of the different bands, the PL spectra of all three samples measured at $10 \mathrm{~K}$ are presented in one graph in Figure 9. 


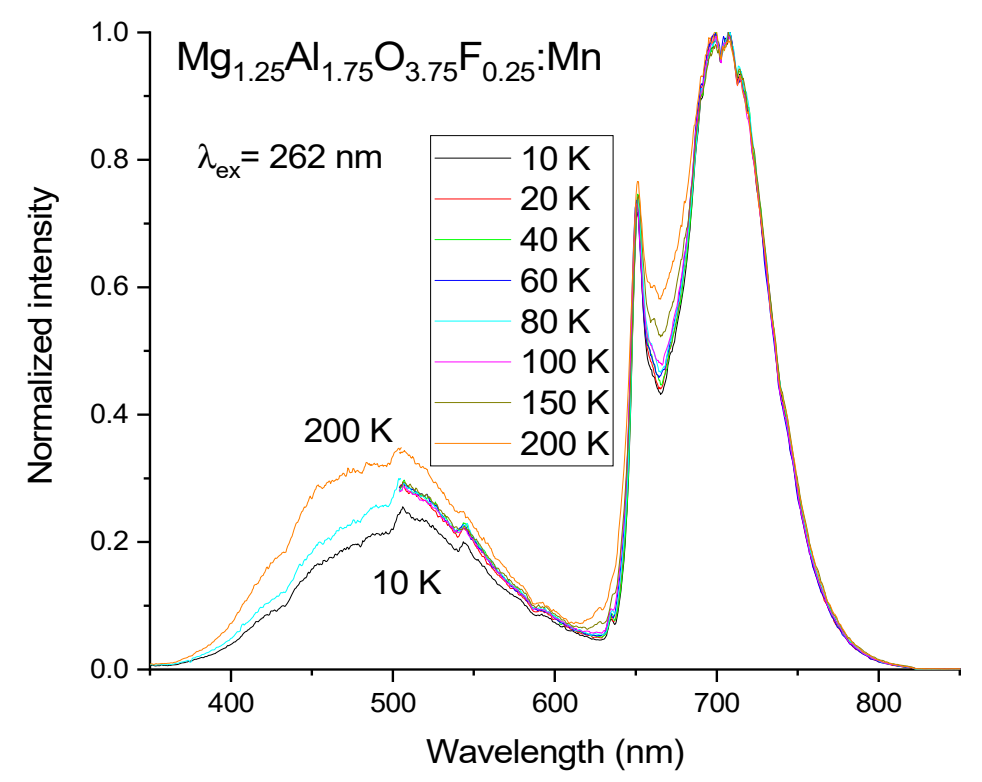

Figure 8. Normalized PL spectra of manganese ions doped $\mathrm{Mg}_{1.25} \mathrm{Al}_{1.75} \mathrm{O}_{3.75} \mathrm{~F}_{0.25}$ (sample III), measured at different temperatures.

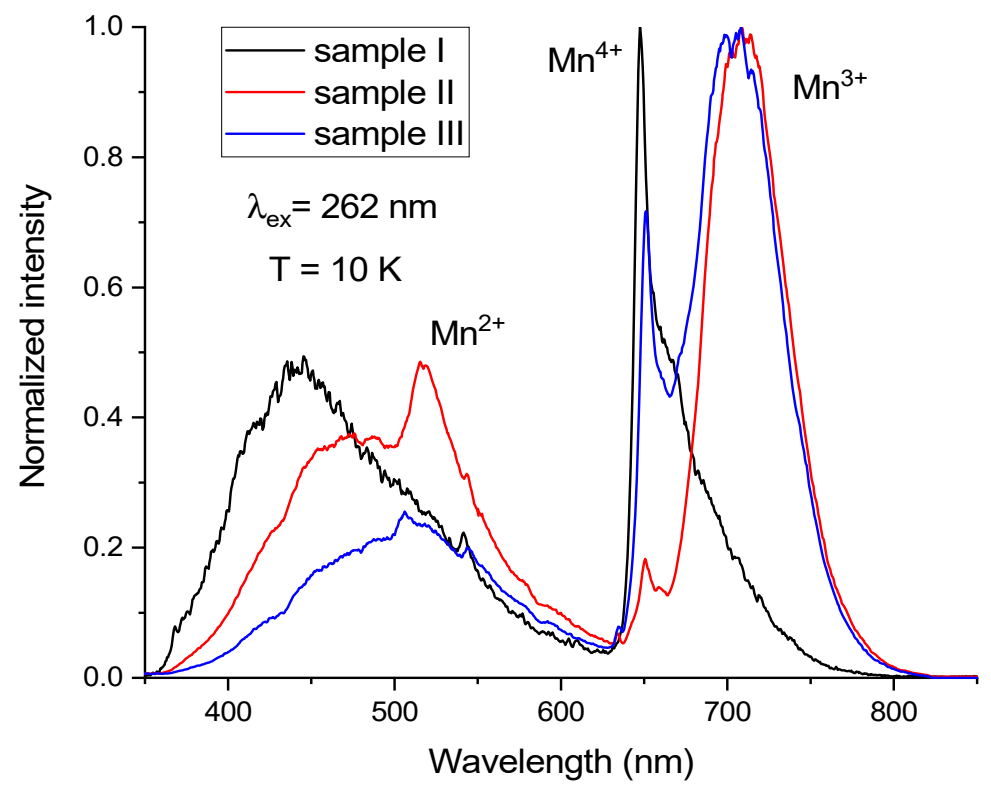

Figure 9. Normalized PL spectra of samples I, II, and III measured at $10 \mathrm{~K}$.

\section{Discussion}

The observed low-temperature and time-resolved properties of the red emission band in the PL spectrum of sample I correspond well to those of $\mathrm{Mn}^{4+}$ luminescence from the $\mathrm{MgAl}_{2} \mathrm{O}_{4}$ spinel studied earlier at room and higher temperatures [15-18]. In particular, the narrow feature of the band at $651 \mathrm{~nm}$ is the zero-phonon line (ZPL) of the $\mathrm{Mn}^{4+2} \mathrm{E} \rightarrow{ }^{4} \mathrm{~A}_{2}$ transition, while the bands of the PL spectrum at longer and shorter wavelengths correspond to Stokes and anti-Stokes vibronic sub-bands, respectively. All these PL spectrum features show inhomogeneous broadening due to the cation disorder caused by inversion in the spinel $\mathrm{MgAl}_{2} \mathrm{O}_{4}$ structure. In particular, the disorder leads to spectral smearing of vibronic lines. This interpretation is confirmed by the results of the low-temperature measurements which have shown that the main peak at $651 \mathrm{~nm}$ considerably narrows with decreasing temperature and the short-wavelength wing of the PL spectrum, i.e., the anti-Stokes vibronic side-band disappears at low temperatures. The 
time-resolved PL spectra of sample I have shown that all the components of the spectrum are due to a decay from the same initial emitting state, i.e., to the ${ }^{2} \mathrm{E} \rightarrow{ }^{4} \mathrm{~A}_{2}$ transition in $\mathrm{Mn}^{4+}$ including the vibronic transitions. Thus, it can be concluded that the synthesis procedure applied to sample I provides stabilization of practically all manganese ions in the tetravalent oxidation state.

The obtained properties of $\mathrm{Mn}^{2+}$ green luminescence under $262 \mathrm{~nm}$ laser excitation also correspond well to those of $\mathrm{Mn}^{2+}$ in different spinel structures studied earlier although overlapping of the $\mathrm{Mn}^{2+}$ emission spectrum with the spectrum of some spinel defect-related emission does not allow studying these properties in detail. Besides that, the efficiency of $\mathrm{Mn}^{2+}$ luminescence excitation is lower when these samples are excited at $262 \mathrm{~nm}$ than in the case of lower-energy excitation.

Some hypotheses can be proposed for the explanation of the nature of the broadband emission at $675 \div 720 \mathrm{~nm}$ which is observed in $\mathrm{MgAl}_{2} \mathrm{O}_{4}: \mathrm{Mn}$ phosphor samples. In particular, broad-band luminescence of $\mathrm{Mn}^{4+}$ ions can be observed instead of the narrowband emission in the case of weak CF strength. The luminescence properties of $\mathrm{d}^{3}$ ions $\left(\mathrm{Mn}^{4+}\right)$ in octahedral coordination are determined by transitions from the states ${ }^{2} \mathrm{E}$ and ${ }^{4} \mathrm{~T}_{2}$ (i.e., the two lowest-energy excited states); moreover, the energy of the ${ }^{4} \mathrm{~T}_{2}$ level is strongly affected by the CF strength. Indeed, the CF strength determines the position of the ${ }^{4} \mathrm{~T}_{2}$ level with respect to the ${ }^{2} \mathrm{E}$ state as well as the crossover point for these levels in the $\mathrm{d}^{3}$ TS diagram. For this reason, in materials where $\mathrm{Mn}^{4+}$ ions are affected by a strong $\mathrm{CF}$, the narrow-band $\mathrm{Mn}^{4+}$ luminescence associated with the transition ${ }^{2} \mathrm{E} \rightarrow{ }^{4} \mathrm{~A}_{2}$ is observed, but in materials with crystallographic sites inducing weak $\mathrm{CF}$, the broadband ${ }^{4} \mathrm{~T}_{2} \rightarrow{ }^{4} \mathrm{~A}_{2}$ emission can be observed from $\mathrm{Mn}^{4+}$. However, the latter transition is spin-allowed, i.e., such luminescence should show a relatively fast decay, at least a faster decay than that obtained in our studies for this band $(\tau \sim 4.0 \mathrm{~ms})$. It could be suggested that the value of the CF strength is near the crossover point for ${ }^{2} \mathrm{E}$ and ${ }^{4} \mathrm{~T}_{2}$ levels, i.e., these levels are thermally coupled, but in this case, the ratio of intensities of the $651 \mathrm{~nm}$ peak and this broad band should strongly change with temperature, which is not observed. Besides that, it is unreasonable to expect that in phosphors based on the same host but obtained under different synthesis conditions $\mathrm{Mn}^{4+}$ ions can occupy octahedral sites inducing such different crystal fields: either strong CF (sample I) or weak CF (sample II).

Another hypothesis is that this broad-band emission in the far-red originates from the luminescence of $\mathrm{Mn}^{2+}$ ions located in octahedral sites. This explanation is proposed, for instance in [23] where the broad-band emission in the far red from the defect-rich $\mathrm{MgAl}_{2} \mathrm{O}_{4}$ spinel doped with $\mathrm{Mn}$ ions is attributed to luminescence of $\mathrm{Mn}^{2+}$ centers in the octahedral sites. If $\mathrm{Mn}^{2+}$ substitutes for $\mathrm{Al}^{3+}$ in the octahedral sites the charge compensation can be reached through inversion without introducing other ions. According to the TS energylevel diagram for $\mathrm{d}^{5}$ electron configuration, luminescence of $\mathrm{Mn}^{2+}$ ions can be observed in significantly different spectral ranges depending on the strength of CF affecting these ions. In particular, luminescence in the green spectral range is expected for $\mathrm{Mn}^{2+}$ ions entering the tetrahedral sites whereas red and even NIR luminescence can be observed from $\mathrm{Mn}^{2+}$ occupying octahedral sites. It should be noted here that in the case of the $\mathrm{d}^{5}$ electron configuration, the TS diagrams for octahedral and tetrahedral coordination are identical by taking into account that the CF strength is stronger for octahedral sites than for tetrahedral ones.

As all the $\mathrm{Mn}^{2+}$ absorption transitions are spin-forbidden; the corresponding bands in the PLE spectrum of $\mathrm{Mn}^{2+}$ can be concealed by the wider and more intense bands caused by spin-allowed transitions within $\mathrm{Mn}^{4+}$. In this case the PLE spectra of such possible far-red $\mathrm{Mn}^{2+}$ luminescence and the red $\mathrm{Mn}^{4+}$ luminescence in the blue and near UV regions can coincide if one considers that the far-red luminescence from $\mathrm{Mn}^{2+}$ is excited by the energy transfer from $\mathrm{Mn}^{4+}$ ions to $\mathrm{Mn}^{2+}$ ions. This similarity of PLE spectra is indeed observed in the experiment for the broad-band far-red luminescence and the red $\mathrm{Mn}^{4+}$ luminescence. On the other hand, the PLE spectrum of $520 \mathrm{~nm}$ emission corresponding to the luminescence of $\mathrm{Mn}^{2+}$ entered into the spinel tetrahedral sites is well reproduced with 
all its specific features, see Figure 6 . Therefore, it is unclear why the respective features are not seen in the PLE spectrum of the observed far-red luminescence if this far-red luminescence originates from the $\mathrm{Mn}^{2+}$ ions entered into octahedral sites. Besides that, one could hardly suggest that $\mathrm{Mn}^{2+}$ ions having an ionic radius of $0.83 \AA$ in octahedral coordination can substitute for $\mathrm{Al}^{3+}$ ions having an ionic radius of $0.535 \AA$ in the same one [24], i.e., the ionic radii of these octahedrally coordinated ions differ by more than $50 \%$, and according to standard crystallographic rules, such substitution is highly unlikely by taking into account that the ratio of $\mathrm{Mg}^{2+}$ and $\mathrm{Mn}^{2+}$ ionic radii in tetrahedral coordination is $0.57 / 0.66 \AA$. In other words, it is most likely that in the spinel $\mathrm{MgAl}_{2} \mathrm{O}_{4}$ structure, the $\mathrm{Mn}^{2+}$ ions occupy the tetrahedral sites but not the octahedral ones.

Generally speaking, it can be assumed that in compounds doped with Mn ions, the octahedral sites contain both $\mathrm{Al}^{3+}$ as well as $\mathrm{Mn}^{3+}$ ions, for which charge compensation is not required. Information on the luminescence behavior of $\mathrm{Mn}^{3+}$ is very limited $[25,26]$. In general, it is expected that in the majority of the hosts, the $\mathrm{Mn}^{3+}$ luminescence is quenched due to the large Jahn-Teller splitting of $\mathrm{Mn}^{3+}$ energy levels. Considering the TS diagram for $\mathrm{d}^{4}$ ions, the broad-band luminescence of $\mathrm{Mn}^{3+}$ entering into the octahedral site can be due to either the spin-allowed ${ }^{5} \mathrm{~T}_{2} \rightarrow{ }^{5} \mathrm{E}$ transition which has typically rather short decay time (of the order of tens $\mu$ s [26]) or the slower spin-forbidden ${ }^{1} \mathrm{~T}_{2} \rightarrow{ }^{5} \mathrm{E}$ transition, depending on the CF strength. The $\mathrm{Mn}^{3+}$ broad-band absorption is due to the strong spin-allowed ${ }^{5} \mathrm{E} \rightarrow{ }^{5} \mathrm{~T}_{2}$ transition, typically located at $500 \div 550 \mathrm{~nm}$, i.e., just in the spectral range where some additional band in the PLE spectrum of emission at $689 \mathrm{~nm}$ is observed for sample II, see Figure 6 . In the spectral range $325 \div 500 \mathrm{~nm}$, absorption by $\mathrm{Mn}^{4+}$ ions dominates and the shape of the PLE spectrum of the broad-band far-red luminescence almost coincides with that of $\mathrm{Mn}^{4+}$ luminescence monitored at $651 \mathrm{~nm}$, which can be simply explained by the overlapping of emission bands of these two kinds of luminescence centers but can be partly due to the presence of the energy transfer from $\mathrm{Mn}^{4+}$ to $\mathrm{Mn}^{3+}$. However, at wavelengths shorter than $\sim 325 \mathrm{~nm}$, the broad-band far-red luminescence is excited more efficiently, which can be due to some kind of $\mathrm{O} 2 \mathrm{p}-\mathrm{Mn} 3 \mathrm{~d}$ charge-transfer transition. The decay time of this broad-band far-red luminescence is rather long (i.e., $\tau \sim 4.0 \mathrm{~ms}$ ) and so this luminescence can be ascribed to the $\mathrm{Mn}^{3+}$ spin-forbidden ${ }^{1} \mathrm{~T}_{2} \rightarrow{ }^{5} \mathrm{E}$ transition. In the presence of charge compensation by extra amounts of $\mathrm{Mg}^{2+}$ ions, the efficient conversion of $\mathrm{Mn}^{3+}$ to $\mathrm{Mn}^{4+}$ takes place, resulting in the appearance of $\mathrm{Mn}^{4+}$ luminescence in sample III and in the complete disappearance of this broad-band far-red luminescence in sample I synthesized under oxidation conditions.

\section{Conclusions}

The obtained low-temperature and time-resolved features of the red emission band characterizing the PL spectrum of the $\mathrm{Mn}^{4+}$-doped $\mathrm{MgAl}_{2} \mathrm{O}_{4}$ sample confirmed the generally accepted model of this luminescence as caused by the $\mathrm{Mn}^{4+2} \mathrm{E} \rightarrow{ }^{4} \mathrm{~A}_{2}$ transitions, including the ZPL located at $651 \mathrm{~nm}$ and the Stokes and anti-Stokes vibronic side-bands, which are broadened by the cation disorder caused by inversion in the spinel crystal structure. In this work it has been shown that the special multi-step annealing procedure applied for the solid-state synthesis of a $\mathrm{MgAl}_{2} \mathrm{O}_{4}: \mathrm{Mn}^{4+}$ phosphor provides the stabilization of practically all manganese ions introduced into the phosphor in the tetravalent state. Furthermore, red-emitting $\mathrm{MgAl}_{2} \mathrm{O}_{4}: \mathrm{Mn}^{4+}$ phosphor synthesized by this method demonstrates good color characteristics (CIE 1931 color coordinates are $\mathrm{x}=0.72 ; \mathrm{y}=0.28$ [18]); it can be therefore considered as promising red phosphor for the realization of warm pc-WLEDs. The broad-band far-red luminescence observed from $\mathrm{MgAl}_{2} \mathrm{O}_{4}$ phosphors containing manganese ions non-stabilized in the tetravalent state has been attributed to spin-forbidden ${ }^{1} \mathrm{~T}_{2} \rightarrow{ }^{5} \mathrm{E}$ transitions of $\mathrm{Mn}^{3+}$ ions substituting for $\mathrm{Al}^{3+}$ ions in the octahedral sites in the spinel structure. Such $\mathrm{MgAl}_{2} \mathrm{O}_{4}: \mathrm{Mn}^{3+}$ phosphors can be used for different lighting applications, among them those related to the agricultural lighting [27].

Author Contributions: Conceptualization, N.K., M.B. and V.M.; methodology, N.K.; formal analysis, V.M.; investigation, G.T., A.P., B.P. and M.V.; data curation, A.P.; writing—original draft preparation, 
V.M.; writing-review and editing, V.M., N.K., G.T., A.P., B.P. and M.V.; project administration, M.B.; funding acquisition, A.P. All authors have read and agreed to the published version of the manuscript.

Funding: This research was funded by the Russian Science Foundation (RSF), grant number 18-1300407 for the synthesis, X-ray analysis, and PLE spectral studies and by Ente Cassa di Risparmio di Firenze (IFAC-CNR, Rif. 2018.1124) for the time-resolved and temperature-resolved PL spectral studies.

\section{Institutional Review Board Statement: Not applicable.}

Informed Consent Statement: Not applicable.

Data Availability Statement: Data is contained within the article. Further numerical data (e.g., spectra shown in Figures) are available on request from the corresponding Author.

Acknowledgments: This work was supported by the Russian Science Foundation (RSF), grant number 18-13-00407 "Synthesis of the new red phosphors based on fluorine-containing materials, doped with optically active manganese ions, for warm white light emitting diodes" and by Ente Cassa di Risparmio di Firenze (Rif. 2018.1124), project "Sviluppo e fabbricazione di fosfori, non contenenti elementi chimici appartenenti al gruppo delle Terre Rare, da usare per costruire dispositivi LED con emissione di luce bianca".

Conflicts of Interest: The authors declare no conflict of interest.

\section{References}

1. Zhou, Q.; Dolgov, L.; Srivastava, A.M.; Zhou, L.; Wang, Z.; Shi, J.; Dramićanin, M.D.; Brik, M.G.; Wu, M. Mn ${ }^{2+}$ and Mn ${ }^{4+}$ red phosphors: Synthesis, luminescence and applications in WLEDs. A review. J. Mater. Chem. C 2018, 6, 2652-2671. [CrossRef]

2. Adachi, S. Review-Mn $\mathrm{Mn}^{4+}$-activated red and deep red-emitting phosphors. ECS J. Solid State Sci. Technol. $2020,9,016001$. [CrossRef]

3. Lin, C.; Chen, W.T.; Liu, R. Phosphors for White LEDs. In Handbook of Advanced Lighting Technology; Karlicek, R., Sun, C.C., Zissis, G., Ma, R., Eds.; Springer: Cham, Switzerland, 2017. [CrossRef]

4. Adachi, S. Photoluminescence spectra and modeling analyses of $\mathrm{Mn}^{4+}$-activated fluoride phosphors: A review. J. Lumin. 2018, 197, 119-130. [CrossRef]

5. Khaidukov, N.; Brekhovskikh, M.; Toci, G.; Patrizi, B.; Vannini, M.; Pirri, A.; Makhov, V. Time-and temperature-resolved luminescence spectroscopy of $\mathrm{LiAl}_{4} \mathrm{O}_{6} \mathrm{~F}$ : Mn red phosphors. J. Lumin. 2019, 216, 116754. [CrossRef]

6. Cao, R.; Xue, H.; Yu, X.; Xiao, F.; Wu, D.; Zhang, F. Luminescence properties and synthesis of $\operatorname{SrMgAl}_{10} \mathrm{O}_{17}: \mathrm{Mn}^{4+}$ red phosphor for white light-emitting diodes. J. Nanosci. Nanotechnol. 2016, 16, 3489-3493. [CrossRef] [PubMed]

7. Wang, B.; Lin, H.; Huang, F.; Xu, J.; Chen, H.; Lin, Z.; Wang, Y. Non-rare-earth BaMgAl $\mathrm{Al}_{10-2 \mathrm{x}} \mathrm{O}_{17}: \mathrm{xMn}^{4+}, \mathrm{xMg}^{2+}: \mathrm{A} \mathrm{narrow-band}^{2}$ red phosphor for use as a high-power warm w-LED. Chem. Mater. 2016, 28, 3515-3524. [CrossRef]

8. Zhang, H.; Zhang, H.; Zhuang, J.; Dong, H.; Zhu, Y.; Ye, X.; Liu, Y.; Lei, B. Effect of $\mathrm{H}_{3} \mathrm{BO}_{3}$ flux on the morphology and optical properties of $\mathrm{Sr}_{2} \mathrm{MgAl}_{22} \mathrm{O}_{36}: \mathrm{Mn}^{4+}$ red phosphors for agricultural light conversion films. Ceram. Int. 2016, 42, 13011-13017. [CrossRef]

9. Sasaki, T.; Fukushima, J.; Hayashi, Y.; Takizawa, H. Synthesis and photoluminescence properties of Mn ${ }^{4+}$-doped magnetoplumbiterelated aluminate $\mathrm{X}$-type $\mathrm{Ca}_{2} \mathrm{Mg}_{2} \mathrm{Al}_{28} \mathrm{O}_{46}$ and $\mathrm{W}$-type $\mathrm{CaMg}_{2} \mathrm{Al}_{16} \mathrm{O}_{27}$ red phosphors. Ceram. Int. 2017, 43, 7147-7152. [CrossRef]

10. Meng, L.; Liang, L.; Wen, Y. An efficient red phosphor $\mathrm{Li}^{+}, \mathrm{Mn}^{4+}$ co-doped $\mathrm{Sr}_{4} \mathrm{Al}_{14} \mathrm{O}_{25}$ for warm white light emitting diodes. Sci. Adv. Mater. 2017, 9, 456-459. [CrossRef]

11. Sasaki, T.; Fukushima, J.; Hayashi, Y.; Takizawa, H. Synthesis and photoluminescence properties of a novel $\mathrm{Sr}_{2} \mathrm{Al}_{6} \mathrm{O}_{11}: \mathrm{Mn}^{4+}$ red phosphor prepared with a $\mathrm{B}_{2} \mathrm{O}_{3}$ flux. J. Lumin. 2018, 194, 446-451. [CrossRef]

12. Zhao, Y.; Shi, L.; Han, Y.-J.; Li, H.-H.; Ji, Z.-X.; Zhang, Z.-W. Luminescent properties of $\mathrm{Zn}^{2+}-\operatorname{doped} \mathrm{CaAl}_{12} \mathrm{O}_{19}: \mathrm{Mn}^{4+}$ deep-red phosphor for indoor plant cultivation. Ceram. Int. 2019, 45, 8265-8270. [CrossRef]

13. Wang, X.; Li, P.; Brik, M.G.; Li, X.; Li, L.; Peng, M. Thermal quenching of $\mathrm{Mn}^{4+}$ luminescence in $\mathrm{SrAl}_{12} \mathrm{O}_{19}: \mathrm{Mn}^{4+}$. J. Lumin. 2019, 206, 84-90. [CrossRef]

14. Li, X.; Chen, Z.; Wang, B.; Liang, R.; Li, Y.; Kang, L.; Liu, P. Effects of impurity doping on the luminescence performance of $\mathrm{Mn}^{4+}$-doped aluminates with the magnetoplumbite-type structure for plant cultivation. Materials 2019, 12, 86. [CrossRef]

15. Wakui, Y.; Shan, Y.J.; Tezuka, K.; Imoto, H.; Ando, M. Crystal-site engineering approach for preparation of $\mathrm{MgB}_{2} \mathrm{O}_{4}: \mathrm{Mn}^{2+}, \mathrm{Mn}^{4+}$ $(\mathrm{B}=\mathrm{Al}, \mathrm{Ga})$ phosphors: Control of green/red luminescence properties. Mat. Res. Bull. 2017, 90, 51-58. [CrossRef]

16. Zhang, Y.; Liu, Y.; Yang, L.; Hu, S.; Wang, Z.; Jing, Z.; Nian, H.; Liu, B.; Zhou, G.; Wang, S. Preparation and luminescence properties of thermally stable $\mathrm{Mn}^{4+}$ doped spinel red-emitting ceramic phosphors. J. Lumin. 2020, 220, 117016. [CrossRef]

17. Khaidukov, N.M.; Brekhovskikh, M.N.; Kirikova, N.Y.; Kondratyuk, V.A.; Makhov, V.N. Luminescence of $\mathrm{MgAl}_{2} \mathrm{O}_{4}$ and $\mathrm{ZnAl}_{2} \mathrm{O}_{4}$ spinel ceramics containing some 3d ions. Ceram. Int. 2020, 46, 21351-21359. [CrossRef] 
18. Khaidukov, N.M.; Brekhovskikh, M.N.; Kirikova, N.Y.; Kondratyuk, V.A.; Makhov, V.N. Luminescent properties of spinels doped with manganese ions. Russ. J. Inorg. Chem. 2020, 65, 1135-1141. [CrossRef]

19. Bosi, F.; Biagioni, C.; Pasero, M. Nomenclature and classification of the spinel supergroup. Eur. J. Mineral. 2019, 3, 183-192. [CrossRef]

20. Cahiez, G.; Alami, M.; Taylor, R.J.K.; Reid, M.; Foot, J.S.; Fader, L.; Sikervar, V.; Pabba, J. Manganese Dioxide. In Encyclopedia of Reagents for Organic Synthesis; Wiley: Hoboken, NJ, USA, 2017. [CrossRef]

21. Song, E.H.; Zhou, Y.Y.; Wei, Y.; Han, X.X.; Tao, Z.R.; Qiu, R.L.; Xia, Z.G.; Zhang, Q.Y. A thermally stable narrow-band greenemitting phosphor $\mathrm{MgAl}_{2} \mathrm{O}_{4}: \mathrm{Mn}^{2+}$ for wide color gamut backlight display application. J. Mater. Chem. C 2019, 7, 8192-8198. [CrossRef]

22. Tanabe, Y.; Sugano, S. On the absorption spectra of complex ions II. J. Phys. Soc. Jpn. 1954, 9, 776-779. [CrossRef]

23. Mohler, R.L.; White, W.B. Influence of structural order on the luminescence of oxide spinels: Manganese activated spinels. Mater. Res. Bull. 1994, 29, 1109-1116. [CrossRef]

24. Shannon, R.D. Revised effective ionic radii and systematic studies of interatomic distances in halides and chalcogenides. Acta Cryst. A 1976, 32, 751-767. [CrossRef]

25. van Die, A.; Leenaers, A.C.H.I.; van der Weg, W.F.; Blasse, G. A search for luminescence of the trivalent manganese ion in solid aluminates. Mater. Res. Bull. 1987, 22, 781-787. [CrossRef]

26. Kück, S.; Hartung, S.; Hurling, S.; Petermann, K.; Huber, G. Optical transitions in $\mathrm{Mn}^{3+}$-doped garnets. Phys. Rev. B 1998, 57, 2203-2216. [CrossRef]

27. Piovene, C.; Orsini, F.; Bosi, S.; Sanoubar, R.; Bregola, V.; Dinelli, G.; Gianquinto, G. Optimal red:blue ratio in led lighting for nutraceutical indoor horticulture. Sci. Hortic. 2015, 193, 202-208. [CrossRef] 